\title{
MODEL PELAKSANAAN METODE MANHAJI DALAM PROGRAM TAFHĪMUL QUR'AN JUZ 1 (SATU)
}

\author{
Sudarno Shobron; Syahrul Ramadhon \\ Fakultas Agama Islam Universitas Muhammadiyah Surakarta \\ E-Mail: ss175@ums.ac.id
}

\begin{abstract}
A lot of Muslims are increasingly distant from the Holy Quran with various reasons such as busy, can not read even not understand the content of the verse that was read. Muhammadiyah as an Islamic da'wah organization that hathe motto ar ruju 'ilal Quran wa Sunnah (back to the Holy Quran and Sunnah) always try to re-grow the love and pride of Muslims to the Quran, one of the efforts is shown by choosing a method that feels easy for all students from the elderly to the elderly to understand the content of the Holy Qur'an, and the method which chosen by Majlis Tabligh Muhammadiyah was the method of manhaji. The purpose of this research is to know the level of difference understanding of students between before and after following program tafhim with manhaji method. Beside that, this research also aim to measure effectiveness of manhaji method as a method to understand the meanings contained in the Holy Quran. This research is field research that using mixed method approach. This research took a case study at Muhammadiyah Boarding School (MBS) Muhammadiyah High School (SMA) Muhammadiyah Bantul (MUHIBA) and Muhammadiyah Branch Chief (PCM) Kretek. Data collection techniques in this research consisted of observation, interviews, questionnaire and documentation. The result of this research shows that the implementation of program of tafhim al Quran with method of manhaji both of MBS MUHIBA and citizen of Muhammadiyah Kretek are done well, there is improvement of ability to understand Holy Quran at student of MBS MUHIBA and citizen of Muhammadiyah Kretek after following program of tafhim al Quran with method of manhaji. It so happens, the result of effectiveness level of manhaji method in program of tafhim al Quran at MBS MUHIBA is Very Effective, and at PCM Kretek is Effective.
\end{abstract}

Keywords: effectiveness, method, manhaji, tafhìm, al Quran

Abstrak: Banyak umat Islam semakin jauh dari al Quran dengan berbagai macam alasan seperti sibuk, tidak bisa membaca bahkan tidak faham dengan kandungan ayat yang dibaca. Muhammadiyah sebagai organisasi dakwah Islam yang memiliki semboyan ar ruju' ilal Quran wa Sunnah (kembali kepada al Quran dan Sunnah) senantiasa berusaha untuk menumbuhkan kembali kecintaan dan kebanggaan umat Islam kepada al Quran. Salah satu usaha tersebut ialah dengan memilih metode yang dirasa tepat untuk memahami al Quran baik bagi para pelajar hingga orang yang berusia lanjut. Metode yang dipilih oleh Muhammadiyah melalui Majlis Tabligh adalah metode manhaji. Tujuan dari penelitian ini adalah untuk mengetahui tingkat perbedaan pemahaman santri antara sebelum dan sesudah mengikuti program tafhìm dengan metode manhaji. Selain itu, penelitian ini juga bertujuan untuk mengukur tingkat efektivitas metode manhaji sebagai metode untuk memahami makna-makna yang terkandung dalam al Quran. Penelitian ini adalah penelitian lapangan (field research) dengan pendekatan mixed method atau metode campuran antara penelitian kualitatif dengan penelitian kuantitatif. Penelitian ini mengambil studi kasus di Muhammadiyah Boarding School (MBS) Sekolah Menengah Atas (SMA) Muhammadiyah Bantul (MUHIBA) dan Pimpinan Cabang Muhammadiyah (PCM) Kretek. Teknik pengumpulan data dalam penelitian ini terdiri dari observasi, wawancara, kuesioner dan dokumentasi. Hasil penelitian ini menunjukkan bahwa pelaksanaan metode manhaji dalam program tafhìm al Quran baik di MBS MUHIBA 
maupun PCM Kretek telah dilaksanakan dengan baik, terjadi peningkatan kemampuan dalam memahami al Quran pada santri MBS MUHIBA dan warga Muhammadiyah Kretek setelah mengikuti program tafhìm al Quran dengan metode manhaji. Adapun tingkat efektivitas metode manhaji dalam program tafhim al Quran di MBS MUHIBA adalah Sangat Efektif, sedangkan tingkat efektivitas di PCM Kretek adalah Efektif.

Kata kunci: Eektivitas, metode, manhaji, tafhìm, al Quran

\section{PENDAHULUAN}

Muhammadiyah merupakan gerakan dakwah amar ma'ruf nahi mungkar. Organisasi ini didirikan KH. A. Dahlan pada 8 Dzulhijjah $1330 \mathrm{H}$ bertepatan dengan 18 November 1912 M di Yogyakarta. ${ }^{1}$ Muhammadiyah terus melakukan dakwah di berbagai bidang termasuk pendidikan. Pada zamannya, apa yang dilakukan KH. A. Dahlandengan pendidikanMuhammadiyah merupakan suatu reformasi dalam dunia pendidikan yang paling mendasar, yakni dengan memadukan pendidikan Belanda yang dianggap "kafir" dengan pendidikan Islam. $^{2}$

Salah satu lembaga pendidikan Muhammadiyah yang semakin berkembang adalah SMA Muhammadiyah Bantul Yogyakarta. SMA Muhammadiyah Bantul, selain membuka program regular juga membuka program unggulan yaitu program pesantren yang diberi nama Muhiba Boarding School (MBS) SMA Muhammadiyah Bantul (selanjutnya disingkat dengan MBS MUHIBA). MBS MUHIBA memilih metode manhaji dalam proses pembelajaran tafhìm al Quran di asrama.

Metode manhaji tidak hanya digunakan di dalam pendidikan formal atau pesantren-pesantren Muhammadiyah saja, tetapi juga digunakan dalam pengajian warga di beberapa cabang Muhammadiyah. Pimpinan Cabang Muhammadiyah (selanjutnya disingkat PCM) Kretek merupakan salah satu dari sekian cabang

1 Yeni Muharomah dan Dwi Budiningsih, Pendidikan Kemuhamdiyahan SD/MI Muhammadiyah kelas 5, (Yogyakarta: Majelis DIKDASMEN PWM DIY, 2012), hlm. 54

2 Zamroni, Percikan Pemikiran Pendidikan Muhammadiyah, (Yogyakarta: Penerbit Ombak, 2014), hlm. 69
Muhammadiyah di Kabupaten Bantul yang menjadikan tafhìm al Quran metode manhaji sebagai pengajian rutin mingguan untuk para warganya. Metode manhaji merupakan metode resmi yang digunakan Majelis Tabligh Muhammadiyah dalam usahanya untuk memudahkan kaum muslimin dalam memahami al Quran. Metode manhaji merupakan metode yang disusun oleh Ustadz Anas Adnan, Lc., M.Ag. Metode manhaji resmi dipilih oleh Majelis Tabligh PP Muhammadiyah berdasarkan hasil Rapat Kerja Nasional (RAKERNAS) Majelis Tabligh Muhammadiyah pada bulan Juli 2011. ${ }^{3}$ Metode manhaji adalah metode memahami al Quran dengan menterjemahkan teks ayat al Quran kata demi kata (perkata), dengan harapan setelah menggunakan metode ini para santri bisa dengan muda membaca, menterjemahkan, dan memahami maksud dari setiap kata yang ada di dalam al Quran. Namun kenyataanya dalam kehidupan sehari-hari masih ada beberapa santri yang belum bisa menterjemahkan teks ayat al Quran secara perkata meskipun dia telah mengikuti program tafhim al Quran dengan metode manhaji.

Penelitian ini penting dilakukan karena mengingat metode manhaji sebagai metode resmi yang digunakan oleh Majelis Tabligh Muhammadiyah dalam usaha tablighnya kepada seluruh lapisan masyarakat baik melalui pendidikan formal di lembagalembaga pendidikan Muhammadiyah maupun pengajian-pengajian yang diselenggarakan oleh pimpinan-pimpinan

3 M. Anas Adnan, Memahami al Quran dengan Metode Manhaji, (Yogyakarta: Majelis Tabligh Pimpinan Pusat Muhammadiyah, 2014), cet. 3, hlm. vii 
cabang Muhammadiyah dibeberapa tempat, sehingga untuk mengetahui pelaksanaan serta tingkat pencapaian target dari metode tersebut maka perlu diadakan penelitian tentang efektivitas metode manhaji dalam program tafhìm al Quran.

Tulisan tentang tafhìm al Quran dengan metode manhaji juga pernah ditulis oleh Ari Anshori dan dimuat dalam jurnal Profetika vol. 16, no.1, Juni 2015. Dalam tulisannya Ari Anshori memfokuskan pada upaya untuk mencari metode tafhim yang tepat agar pesan-pesan yang terkadung di dalam al Quran dapat tersampaikan dengan tepat sesuai dengan teks dan konteks yang dimaksud. Berdasarkan penelitiannya Ari menyimpulkan bahwa di dalam al Quran terdapat ayat-ayat yang muhkamat dan mutasyabihat oleh karena itu dibutuhkan alat bantu untuk mengurai ayat-ayat tersebut agar maksud dari ayat itu dapat difahami dengan baik oleh pembaca, dan alat yang perlu mendapatkan apresiasi salah satunya adalah metode manhaji, karena metode ini dirasa sangat membantu dalam mengurai berbagai macam kemusykilan atau masalah dalam memahami ayat-ayat yang terkandung di dalam al Quran.

Perbedaan penelitian ini dengan penelitian Ari Anshori terletak pada fokus kajian yaitu jika penelitian yang dilakukan oleh Ari Anshori adalah untuk mengurai corak metode dalam upaya atau usaha untuk memahami (tafhīm) al Quran, sedangkan penelitian yang peneliti lakukan adalah untuk mengetahui tingkat efektivitas metode manhaji untuk memahami al Quran selain itu objek penelitian ini terletak di MBS MUHIBA dan PCM Kretek

Fokus penelitian ini, maka peneliti merumuskan pokok masalah sebagai berikut: 1). bagaimana pelaksanaan metode manhaji di MBS MUHIBA dan PCM Kretek? 2). Bagaimana tingkat peningkatan kemampuan santri MBS MUHIBA dan warga Muhammadiyah Kretek setelah mengikuti program tafhìm al Quran metode manhaji? 3). Bagaimana tingkat efektivitas metode manhaji dalam program tafhim al Quran di MBS MUHIBA dan PCM Kretek?

\section{METODE PENELITIAN}

Metode penelitian yang digunakan oleh peneliti dalam penelitian ini menggunakan metode campuran atau mixed method. Menurut Creswell dan Plano Clark seperti yang dikutip Creswell dalam bukunya Riset Pendidikan; Perencanaan, pelaksanaan dan ealuasi riset kualitatif dan kuantitatif menyatakan bahwa penelitian mixed method adalah suatu prosedur untuk mengumpulkan, menganalisis dan mencampur metode kuantitatif dan lualitatif dalam suatu penelitian atau serangkaian penelitian untuk memahami permaslahan penelitian. ${ }^{4}$

Lokasi dan subjek penelitian. Penelitian ini bertempat di MBS MUHIBA dan PCM Kretek Bantul, adapun subjek atau informan utama penelitian yaitu seluruh santri angkatan pertama MBS MUHIBA dan peserta pengajian tafhìm al Quran PCM Kretek. Sedangkan subjek atau informan tambahan yaitu orang-orang yang terlibat dalam program tafhīm al Quran baik di MBS MUHIBA maupun di PCM Kretek

Pendekatan yang digunakan dalam penelitian ini adalah pendekatan psikologi pendidikan. Adapun teknik pengumpulan data yang digunakan oleh peneliti yaitu dengan memadukan antara pengumpulan data penelitian kualitatif dan penelitian kuantitatif, yaitu wawancara, observasi, dan angket atau kuesioner, selain menggunakan ketiga teknik tersebut peneliti juga menggunakan dokumentasi sebagai sumber tambahan dalam mengumpulkan data. ${ }^{5}$

Analisis data adalah proses mengorganisasikan dan mengurutkan data ke dalam pola, kategori, dan satuan dasar sehingga dapat ditemukan tema dan dapat

4 John Creswell, Riset Pendidikan; perencanaan, Pelaksanaan dan Evaluasi Riset Kualitatif dan Kuantitatif, (Yogyakarta: Pustaka Pelajar, 2015), hlm. 1088

5 John Creswell, Riset Pendidikan; perencanaan, Pelaksanaan dan Evaluasi Riset Kualitatif dan Kuantitatif, (Yogyakarta: Pustaka Pelajar, 2015), hlm. 1088 Lexy J. Moleong, Metodologi Penelitian Kualitatif, (Bandung: Rosda Karya, 1995), hlm. 
dirumuskan hipotesis kerja seperti yang disarankan oleh data $^{5}$ dalam penelitian kualitatif dibagi ke dalam dua tahapan yaitu (a) analisis ketika di lapangan, dan (b) analisis pascalapangan. Adapun jenis skala yang digunakan oleh peneliti untuk menganalisa hasil angket adalah jenis skala likert. $^{6}$

Dari keterangan di atas disebutkan pencapaian persentase interpretasi skor efektivitas. Kriteria interpretsi skor efektivitas di atas digunakan sebagai acuan penilaian terhadap peningkatan pemahaman para santri dalam memahami al Quran dengan tepat dan untuk mengetahui tingkat pencapaian efektivitas penggunaan metode manhaji dalam program tafhìm al Quran di MBS MUHIBA dan PCM Kretek. ${ }^{7}$

\section{HASIL DAN PEMBAHASAN}

MBS MUHIBA melaksanakan pembelajaran tafhim al Quran setiap hari ahad malam sampai jumat sore mulai pukul 18.00 atau setelah sholat maghrib sampai pukul 20.00, dalam pelaksanaan tafhìm al Quran dengan metode manhaji ini dilaksanakan dengan bimbingan 2 orang ustadz dalam 1 halaqoh atau kelompok yang terdiri dari 20 orang santri, Dalam pelaksanaannya jadwal program tafhìm al Quran dengan metode manhaji mengalami beberapakali perubahan jam, di awal tahun ajaran pelaksanaan program tafhìm al Quran ini dilaksanakan pada waktu malam hari setelah sholat maghrib sampai pukul 20.00, kemudian dirubah menjadi setelah sholat subuh dengan pertimbangan ketika pagi hari masih segar sehingga diharapkan para santri akan mudah menghafal dan menerima materi, namun setelah dilakukan evaluasi ternyata pemberian materi tafhìm

6 John Creswell, Riset Pendidikan; perencanaan, Pelaksanaan dan Evaluasi Riset Kualitatif dan Kuantitatif, (Yogyakarta: Pustaka Pelajar, 2015), hlm. 1088.

7 John Creswell, Riset Pendidikan; perencanaan, Pelaksanaan dan Evaluasi Riset Kualitatif dan Kuantitatif, (Yogyakarta: Pustaka Pelajar, 2015), hlm. 1088. al Quran setelah sholat subuh tidak dapat diikuti para santri dengan baik karena banyak santri yang tidur ketika pelajaran, sehingga diputuskan untuk program tafhìm al Quran ini dikembalikan pada waktu malam hari.

Program tafhìm al Quran dengan metode manhaji di PCM Kretek secara resmi dimulai pada bulan April tahun 2015, program ini dibuka secara resmi oleh Ustadz Zaini Munir Fadloli, M.Ag selaku wakil ketua Majelis Tabligh Pimpinan Pusat Muhammadiyah yang juga mendapatkan tugas sebagai pemimpin dan koordinator gerakan tafhìm al Quran. PCM Kretek melaksanakan program tafhim al Quran setelah mendengarkan laporan dari utusan PCM Kretek dalam ToT (Training of Trainer) metode Manhaji oleh Pimpinan Daerah Muhammadiyah Kabupaten Bantul, laporan dari utusan PCM Kretek dalam ToT tersebut dikuatkan oleh beberapa pengurus yang sebelumnya mengikuti program tafhìm al Quran dengan merode manhaji yang diselenggarakan oleh Majelis Tabligh Pimpinan Pusat Muhammadiyah di Madrasah Muallimin Yogyakarta setiap selasa malam.

Pelaksanaan pembelajaran tafhìm al Quran dengan metode manhaji seperti yang digagas oleh Ustadz Anas Adnan dibagi menjadi tiga tahap yang terdiri dari tahap analitik, tahap sintetik, tahap evaluasi. Adapun pelaksanaan program tafhìm al Quran di MBS MUHIBA dan PCM Kretek sebagai berikut:

\section{Tahap Analitik}

Tahap analitik terdiri dari tiga tahap, yaitu tahap membaca, tahap mengartikan kata demi kata, tahap memahami arti ayat

\section{Tahap Membaca}

Tahap pertama ini dilakukan dengan cara ustadz membacakan sebuah ayat kemudian ditirukan oleh peserta atau santri, jika ayat yang dibaca panjang maka ustadz bisa menjadikan ayat tersebut dalam beberapa potongan-potongan ayat. 
Pelaksanaan tahap membaca di MBS MUHIBA telah dilaksanakan dengan sangat baik. Hal ini ditunjukkan dengan nilai persentase responden sebesar $92 \%$. Dalam praktiknya di MBS MUHIBA ustadz tidak selalu menjadi pemimpin dalam membaca al Quran tetapi ustadz lebih sering menunjuk salah satu santri yang dirasa bacaannya sudah baik untuk memimpin teman-temannya membaca ayat yang akan dipelajari, dan ini tidak hanya pada satu santri saja karena di MBS MUHIBA ada beberapa santri yang telah pandai membaca al Quran.

Adapun pelaksanaan tahap membaca di PCM Kretek juga telah dilaksanakan dengan sangat baik, hal ini didukung dengan persentase nilai peserta yang menunjukkan angka $83 \%$. Dalam pelaksanaan tahap membaca di PCM Kretek ini tidak berbeda jauh dengan MBS MUHIBA terkadang pengurus juga menunjuk salah satu peserta untuk membacakan ayat yang akan dipelajari dan kemudian diikuti oleh peserta yang lain.

\section{Tahap Mengartikan Kata demi Kata}

Tahap ini tidak berbeda jauh dengan tahap membaca hanya saja dalam tahap ini ustadz membaca kata demi kata beserta artinya dalam satu ayat dan ditirukan santri, kemudian ustadz memberikan waktu kepada santri untuk menghafalnya dan selanjutnya meminta santri untuk memperdengarkan hafalannya kepada ustadz secara bergantian. Tahap ini dapat dibagi dalam beberapa langkah yaitu:

Pertama, ustadz menuntun membaca terjemah perkata ayat al Quran Tahap ini telah dilaksanakan dengan sangat baik di MBS

MUHIBA, hal ini dibuktikan dengan persentase nilai santri sebesar $89 \%$. penilaian ini berdasarkan pada kemampuan ustadz dalam menuntun para santri dalam membaca terjemah perkata dari ayat yang sedang dibaca serta kemampuan ustadz dalam memberikan waktu kepada santri untuk menghafalkan terjemah atau arti dari kata-kata yang sudah diberikan.

Pelaksanaan langkah ini di PCM Kretek telah dilaksanakan dengan baik hal ini berdasarkan persentase sebesar $80 \%$. Pelaksanaan tahap mengartikan kata demi kata ini, baik di MBS MUHIBA maupun di PCM Kretek, dilaksanakan dengan metode ustadz membaca terlebih dahulu kata demi kata beserta artinya dari ayat yang dipelajari kemudian diikuti santri secara bersamasama, setelah ustadz mengulangi beberapa kali, kemudian ustadz hanya membaca kata demi kata dari ayat yang sedang dipelajari secara acak (random) dan para santri diminta menjawab dengan menyebutkan arti dari kata yang dibaca ustadz.

Kedua, ustadz menunjuk atau meminta santri menyetorkan hafalan terjemah kata demi kata

Langkah ini dilaksanakan setelah ustadz memberikan waktu kepada santri untuk menghafalkan terjemah perkata dari ayat yang sedang dipelajari kemudian ustadz menunjuk santri secara acak untuk memperdengarkan hafalan terjemah perkata dari ayat yang sudah dituntunkan ustadz sebelumnya.

Pelaksanaan tahap ini di PCM Kretek sedikit berbeda dengan di MBS MUHIBA, jika di MBS MUHIBA ustadz menunjuk santri secara acak untuk menterjemahkan kata yang disebutkan, maka di PCM Kretek ini dilaksanakan setelah ustadz hanya membaca kata dalam Bahasa Arab kemudian santrimenyebutkan artinya selama beberapa kali, kemudian dilanjutkan dengan santri menyetorkan hafalan terjemah perkatanya dengan cara satu santri membaca satu ayat penuh dengan membaca al Quran tanpa terjemah yang telah disiapkan sedangkan artinya dengan cara hafalan, dan langkah ini dilakukan dengan cara urut tempat duduk atau sesuai dengan kesiapan santri dalam menyetorkan hafalannya,.

\section{Tahap Memahami Arti Ayat}

Tahap selanjutnya adalah memahami arti ayat. Dalam tahap ini ustadz menjelaskan terjemah atau tafsir dari ayat 
yang dibaca, dalam tahap ini yang tidak kalah penting juga adalah kemampuan ustadz dalam menyampaikan materi yang sedang dipelajari, karena dalam tahap ini ustadz dituntut untuk benar-benar menguasai kandungan ayat yang sedang dipelajari,

\section{Tahap sintetik}

Setelah memahami setiap ayat dan dilanjutkan dengan merangkai ayat tersebut dengan ayat sebelumnya, dengan harapan jika ayat-ayat tersebut saling berkaitan maka peserta akan mendapatkan pemahaman secara utuh dari ayatayat yang saling berkaitan dengan ayat sebelumnya, sebaliknya jika antara ayat tersebut dengan ayat sebelumnya tidak saling berkaitan maka santri akan mengerti eksistensi masing-masing ayat. Tahap ini akan terlaksana dengan baik jika ustadz yang membimbing program tafhìm al Quran memiliki keilmuan dan wawasan yang sangat luas dan mendalam.

\section{Tahap Evaluasi}

Setelah tahap analitik dan sintetik dilaksakan dengan baik maka tahap selanjutnya adalah tahap evaluasi. Maksud dari tahap evaluasi ini adalah mengevaluasi secara klasikal atau individual baik secara urut maupun acak dari awal hingga akhir materi dalam setiap tatap muka tersebut.

Pelaksanaan tahap evaluasi di MBS MUHIBA dilaksanakan setiap dua hari sekali, hal ini dikarenakan satu hari digunakan untuk mempelajari ayat baru dan satu hari digunakan untuk menghafal dan menyetorkan hafalan. Adapun pelaksanaan tahap evaluasi di PCM Kretek tidak selalu dilaksanakan di akhir pertemuan atau setiap dua pertemuan sekali seperti halnya di MBS MUHIBA, akan tetapi tahap evaluasi di PCM Kretek dilaksanakan setelah ustadz membimbing para santri untuk menghafalkan terjemahan perkata dari ayat yang dipelajari, dan hal ini telah dikonsultasikan oleh ustadz Zaini Munir, M.Ag selaku koordinator program tafhìm al Quran yang telah ditunjuk oleh Majelis Tabligh Pimpinan Pusat Muhammadiyah.

Berdasarkan data di atas dapat kita temukan bahwa terdapat beberapa teknis pelaksanaan metode manhaji yang berbeda dengan yang dirumuskan sejak awal oleh ustadz Anas Adnan selaku penggagas metode manhaji. Akan tetapi secara umum semua tahapan-tahapan yang sudah ditetapkan oleh ustadz Anas Adnan telah dilaksanakan dengan sangat baik oleh pengurus MBS MUHIBA dan PCM Kretek dalam pelaksanaan program tafhìm al Quran di lembaga masing-masing, sehingga dapat kita simpulkan bahwa pelaksanaan program tafhìm al Quran dengan metode manhaji baik di MBS MUHIBA maupun di PCM Kretek sudah dilaksanakan dengan sangat baik sesuai dengan konsep rumusan yang digagas oleh Ustadz Anas Adnan baik dalam tahap analitik, sintetik, dan tahap evaluasi

Suatu metode pembelajaran dikatakan efektif jika telah memenuhi indikatorindikator efektivitas. Indikator efektivitas ada 3 yaitu: ketercapaian tujuan dan target, ketercapaian waktu yang telah ditentukan dan tingkat prestasi yang dicapai siswa.

\section{Ketercapaian target}

Tujuan dari metode manhaji sebagaimana yang telah dicanangkan oleh Ustadz Adnan Anas ada tiga yaitu tujuan materil, tujuan moral dan tujuan struktural.

\section{Tujuan Materil}

Tujuan materil yang ingin dicapai dari metode manhaji adalah agar masyarakat mampu memahami al Quran dan kemudian melaksanakannya dalam kehidupan sehari-hari baik secara individu maupun masyarakat. Menurut santri MBS MUHIBA metode manhaji sangat bermanfaat dalam membantu memahami arti setiap kata dalam al Quran, hal ini dibuktikan dengan persentase nilai sebesar $88 \%$. Pemahaman terhadap setiap kata al Quran sangat berpengaruh pada kemampuan santri untuk memahami kandungan satu ayat 
penuh dari al Quran, hal ini dibuktikan dengan persentase nilai kemanfaatan metode manhaji dalam memahami ayat al Quran secara penuh menurut santri MBS MUHIBA sebesar $85 \%$. Selain berdasarkan nilai tersebut, hal ini juga dibuktikan dengan santri dapat menjawab pertanyaan dewan juri tentang kandungan ayat dalam lomba cerdas cermat antar pelajar di Kabupaten Bantul.

Peserta manhaji di PCM Kretek tidak berbeda jauh dari santri MBS MUHIBA dalam memberikan penilaian atas manfaat metode manhaji dalam membantu untuk memahami setiap kata di dalam al Quran yaitu sebesar $86 \%$, begitu juga dalam kemanfaatan metode manhaji dalam memahami ayat al Quran secara penuh yaitu sebesar $83 \%$

\section{Tujuan Moral}

Tujuan moral yang ingin dicapai adalah agar umat Islam tidak meninggalkan generas-generasi lemah baik lemah dalam fisik maupun lemah psikis karena generasi muda semakin jauh dari al Quran, bahkan sebaliknya program tafhìm al Quran dengan metode manhaji ini ingin menciptakan generasi-generasi yang kuat iman dan taqwanya serta bagus akhlaknya dikarenakan mereka cinta terhadap al Quran.

\section{Tujuan Struktural}

Maksud dari tujuan struktural ini adalah agar umat Islam mampu memahami al Quran secara sistematis dan terstruktur mulai dari mampu membaca al Quran dengan baik kemudian mengetahui arti atau makna dari setiap kata yang terkandung di dalamnya, dilanjutkan dengan mengetahui perubahan-perubahan kata yang terjadi di dalam satu kata kemudian dilanjutkan dengan memahami susunan kalimat hingga sampai memahami jiwa dan gaya bahasa (balagoh) yang digunakan oleh Allah swt di dalam al Quran.

Ada 3 responden dari para santri MBS MUHIBA yang pernah mengikuti metode lain dalam program tafhìm al Quran yaitu metode tamyiz. Dua dari responden tersebut menilai bahwa metode tamyiz tersebut lebih bagus untuk program tafhim al Quran dibandingkan dengan metode manhaji dalam program tafhim al Quran, hal ini dikarenakan dalam metode tamyiz sangat mudah menghafalnya bahkan sampai pada nahwu dan shorofnya hal ini dikarenakan metode tamyiz didukung dengan media lain yaitu media musik dan dalam metode tamyiz. Adapun satu responden yang lain menilai bahwa metode manhaji lebih baik dibandingkan metode tamyiz untuk memahami al Quran dikarenakan dalam metode manhaji mengartikan al Qurannya dipotong-potong. Sedangkan responden dari PCM Kretek hanya satu yang pernah mengikuti metode lain yaitu metode cara cepat membaca kitab 6 jam, menurut responden tersebut metode manhaji lebih bagus untuk program tafhim al Quran karena di dalam metode manhaji terdapat pembahasan tentang akar katanya bahkan sampai bina'nya.

Berdasarkan data-data tersebut dapat kita simpulkan bahwa secara umum tujuan dari metode manhaji yang diharapkan oleh ustadz Anas baik di MBS MUHIBA maupun di PCM Kretek telah tercapai.

\section{Ketercapaian waktu}

Mengingat peserta yang beragam baik dari segi usia maupun dari segi kesibukan maka Ustadz Anas tidak menentukan target waktu yang harus ditempuh dalam menyelesaikan metode manhaji karena semuanya dikembalikan pada tempat penyelenggara masing-masing karena mereka yang lebih mengetahui kondisi santri dan peserta di masing-masing tempat penyelenggara tersebut, semakin cepat daya tangkap peserta terhadap materi maka akan semakin cepat juga metode manhaji terselesaikan.

Satu tahap pada program tafhìm di MBS MUHIBA dengan metode manhaji ditargetkan dapat diselesaikan dalam waktu satu semester, dalam praktiknya target ini 
dapat dilaksanakan dengan baik di MBS MUHIBA. Adapun pelaksanaan manhaji di PCM Kretek secara eksplisit tidak dicantumkan dalam dalam kontrak belajar antara pengurus, pengasuh dan peserta tafhìm di PCM Kretek namun berdasarkan pengalaman pengurus yang telah mengikuti program tahim al Quran dengan metode manhaji di tempat lain rata-rata juz 1 dalam metode ini dapat diselesaikan dalam jangka waktu satu tahun, maka secara implisit para pengurus menargetkan program tafhìm al Quran juz 1 dengan metode manhaji ini maksimal diselesaikan dalam 1 tahun. Namun dalam prakteknya program tafhìm al Quran juz 1 dengan metode manhaji ini dapat diselesaikan dalam jangka waktu sekitar 8 bulan.

\section{Tingkat Prestasi}

Santri MBS MUHIBA merasa mengalami peningkatan pemahaman terhadap al Quran yang dia baca setelah mengikuti program tafhìm al Quran dengan metode manhaji $81 \%$ artinya bahwa metode manhaji sangat efektif untuk diterapkan di MBS MUHIBA selain itu peningkatan kemampuan santri dalam memahami al Quran setelah mengikuti program tafhìm dengan metode manhaji ini juga dibuktikan dengan jawaban santri yang tept ketika mengikuti lombba cerdas cermat antar sekolah yang berkenaan dengan pemahaman al Quran meskipun ayat yang diajukan sebagai soal bukanlah ayat yang diajarkan dalam pembelajaran di MBS MUHIBA

Para peserta program tafhìm al Quran di PCM Kretek mengalami peningkatan pemahaman terhadap ayat yang dibaca sebesar $65 \%$ yang berarti bahwa metode manhaji efektif digunakan untuk program tafhìm al Quran di PCM Kretek

\section{PENUTUP}

Berdasarkan hasil penelitian tentang efektivitas metode manhaji dalam program tafhìm al Quran juz 1 di MBS MUHIBA dan PCM Kretek dapat ditarik kesimpulan sebagai berikut:

1. Pelaksanaan metode manhaji di MBS MUHIBA dan PCM Kretek telah dilaksanakan dengan baik.

2. Terjadi peningkatan kemampuan memahami al Quran pada diri santri.

MBS MUHIBA sebesar 81,\% setelah mengikuti program tafhim al Quran dengan metode manhaji. Sedangkan peningkatan kemampuan warga Muhammadiyah Kretek sebesar 65\% setelah mengikuti program tafhìm al Quran dengan metode manhaji. Tingkat efektivitas metode manhaji dalam program tafhim al Quran di MBS MUHIBA Sangat Efektif, dan pada program tafhìm al Quran di PCM Kretek Efektif

\section{DAFTAR PUSTAKA}

Adnan, M. Anas. 2014. Memahami al Quran dengan Metode Manhaji (cet. 3). Yogyakarta: Majelis Tabligh Pimpinan Pusat Muhammadiyah.

Arikunto, Suharsimi 1996. Prosedur Penelitian. Jakarta: Rineka Cipta.

Creswell, John. 2015. Riset Pendidikan; perencanaan, Pelaksanaan dan Evaluasi Riset Kualitatif dan Kuantitatif. Yogyakarta: Pustaka Pelajar.

Moleong, Lexy J. 1995. Metodologi Penelitian Kualitatif. Bandung: Rosda Karya.

Muharomah, Yeni dan Dwi Budiningsih. 2012 Pendidikan Kemuhamdiyahan SD/ MI Muhammadiyah kelas 5. Yogyakarta: Majelis DIKDASMEN PWM DIY.

Riduwan. 2013. Skala Pengukuran Variabel-Variabel Penelitian. Bandung: Alfabeta.

Zamroni. 2014. Percikan Pemikiran Pendidikan Muhammadiyah. Yogyakarta: Penerbit Ombak. 